\title{
The Dynamics of Vadose Zone Transport: A Field and Modeling Study using the Vadose Zone Observatory
}

C.R. Carrigan

January 1, 2001

U.S. Department of Energy

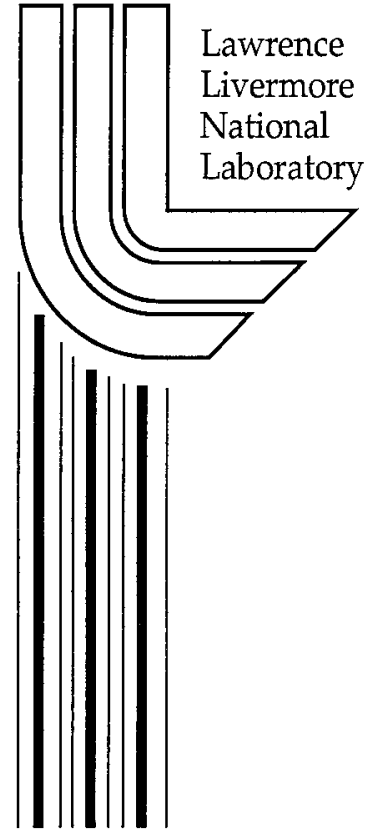




\section{DISCLAIMER}

This document was prepared as an account of work sponsored by an agency of the United States Government. Neither the United States Government nor the University of California nor any of their employees, makes any warranty, express or implied, or assumes any legal liability or responsibility for the accuracy, completeness, or usefulness of any information, apparatus, product, or process disclosed, or represents that its use would not infringe privately owned rights. Reference herein to any specific commercial product, process, or service by trade name, trademark, manufacturer, or otherwise, does not necessarily constitute or imply its endorsement, recommendation, or favoring by the United States Government or the University of California. The views and opinions of authors expressed herein do not necessarily state or reflect those of the United States Government or the University of California, and shall not be used for advertising or product endorsement purposes.

This work was performed under the auspices of the U. S. Department of Energy by the University of California, Lawrence Livermore National Laboratory under Contract No. W-7405-Eng-48.

This report has been reproduced

directly from the best available copy.

Available to DOE and DOE contractors from the

Office of Scientific and Technical Information

P.O. Box 62, Oak Ridge, TN 37831

Prices available from (423) 576-8401

http://apollo.osti.gov/bridge/

Available to the public from the

National Technical Information Service

U.S. Department of Commerce

5285 Port Royal Rd.,

Springfield, VA 22161

http://www.ntis.gov/

$\mathrm{OR}$

Lawrence Livermore National Laboratory

Technical Information Department's Digital Library

http://www.llnl.gov/tid/Library.html 


\title{
EMSP
}

\section{Annual Report}

\author{
$1^{\text {st }}$ Year of Project
}

\section{The Dynamics of Vadose Zone Transport: A Field and Modeling Study Using the Vadose Zone Observatory}

\author{
Charles R. Carrigan, P.I., Lawrence Livermore National Laboratory
}

\author{
Project: 70149
}

\section{Research Objective}

A stated need of the DOE EM program is a better understanding of basic vadose zone fluid flow and contaminant transport processes for the purpose of making improved estimates of contaminant release rates and fluxes across the vadose zone to the water table at DOE sites such as the tank farms at Hanford. We investigate details of the modes of contaminant transport with the aid of infiltration experiments designed to elucidate how vadose zone characteristics such as preferential pathways, heterogeneities, and relative permeabilities influence the transport of contamination in liquid, gas and colloidal phases to the water table. Beyond enhancing our basic understanding of vadose zone transport processes, this EMSP project is designed result in a vadose-zone-transportcharacterization methodology that can be generalized to other DOE sites.

\section{Research Facility/Tools/Personnel}

To accomplish these objectives, we are using the newly developed Vadose Zone Observatory (VZO) at Lawrence Livermore National Laboratory (LLNL) to carry out a cost-effective study of multiphase fluid flow and colloidal transport in a heterogeneous unsaturated zone bearing dynamic resemblance to one type of Hanford vadose regime. The observatory (Fig. 1) consists of almost twenty instrumented boreholes and monitoring wells which traverse the 70-foot unsaturated zone including eight wells containing electric resistance tomography (ERT) arrays, four wells for electromagnetic induction tomography (EIT) and water table sampling, and four boreholes with multilevel gas-sampling ports, soil temperature sensors, gypsum blocks, tensiometers and lysimeters. The observatory uses several multichannel data loggers to continuously store information about surface barometric pressure, subsurface gas-phase pressure, subsurface temperature, capillarity and water-table levels that is downloaded into computers for later analysis. Using the capabilities of the VZO, we will continuously monitor the progress of an infiltration event simultaneously using both geophysical volumetric imaging techniques as well as more conventional hydrologic measurements (e.g., subsurface temperature, gas-phase pressure, tensiometry and lysimetry) that involve making observations at discrete points throughout the infiltration volume. An advantage of this approach is that volumetric imaging provides a context for interpreting the discrete 
observations, while discrete measurements provide a more detailed picture of changes in the vadose zone that cannot be obtained from the volumetric imaging observations themselves. Beyond this, the VZO permits samples of moisture and gases to be taken from many different depths in the vadose zone and from the water table. This ability to sample is critical to our infiltration experiments, which include a variety of chemical and isotopic gas- and liquid-phase tracers and colloidal particles. The release of chemical and isotopic tracers during infiltration events is an important feature of these proposed experiments since such tracers permit evaluation of the potentially complicated relationship between actual chemical transport and fluid flow in the unsaturated zone as determined by ERT or other imaging methods. In future experiments, LLNL's NUFT (Non-isothermal Unsaturated Flow and Transport) computer program will be used to develop diagnostic models that serve as a framework for interpreting the wide variety of observations obtained during an infiltration experiment. Finally, by carrying out some infiltration experiments jointly with other LLNL principal investigators and a geophysical instrumentation company, we will leverage our effort as well as collaborate with them in developing improved subsurface imaging interpretations and technologies based upon the ERT and electromagnetic induction methods. In support of DOE educational programs, some of the work this year involved the participation of an MS-level student intern as well as a postdoctoral researcher (See letter of acknowledgement below from the Defense Nuclear Facilities Safety Board).

\section{Research Progress \& Implications}

Two infiltration experiments were carried out during the first year of this project. The first experiment involved releasing 400 gallons of Hetch Hetchy water without tracers into the central infiltration hole at a depth of approximately $5 \mathrm{~m}$. Before and after the release, water was drawn from adjacent wells in an attempt to determine the tracer load already residing in the vadose zone that is released to the water table during an infiltration event. Previous infiltration events have involved the use of a variety of groundwater tracers including lithium bromide, potassium iodide, sodium chloride and a mixture of rare isotopes of several noble gases. (The sodium chloride was added occasionally to enhance the electrical conductivity of the infiltrant for subsurface imaging purposes.)

Modeling and experiments carried out as part of an earlier EMSP project (54950) indicate that the vadose zone is effective for retaining tracers that are released into the soil. The tracer-laden water is then held by capillarity until an infiltration event can perturb the moisture retention curve causing a release of vadose zone groundwater at the watertable level. Figure 1 illustrates the iodide and bromide levels observed in two monitoring wells over a period of approximately 70 days. The first infiltration experiment involving unspiked Hetch Hetchy water occurred on about day 235 in the plot. The observed spikes in the the bromide and iodide concentrations occur solely because of the addition of vadose zone water that has enhanced concentrations of these two tracers from earlier experiments (EMSP \#54950). This kind of observation is most useful for predicting metering rates of contamination to the watertable as a result of infiltration associated with rain, flooding or irrigation of the surface. Similar information obtained at locations such 
as the Hanford FX tank farms or INEEL is required to achieve a major DOE-EM goal of estimating the flux of contamination to the watertable owing to natural infiltration events.

The second event involved the release of 400 gallons (1500 l) of bromide and sodium chloride spiked Hetch Hetchy water on approximately day 248 in Figure 1. This event produced a smaller response in concentration changes of bromide and iodide at the watertable. This result is slightly surprising considering that the water release contained a high level of bromide tracer. One possibility that is being investigated is that swelling of clayey soils associated with the first salt-free injection may have reduced the downward propagation of excess vadose zone water to the watertable that was associated with the second injection event.

In the second event, baseline ERT observations indicated rapid changes in vadose zone saturation down to the water table level in a few hours. ERT is sensitive to resistivity changes in the 2-5\% range. An electromagnetic induction tomography (EMTT) tool (Fig. 2) was simultaneously fielded in collaboraition with Electromagnetic Instruments (EMI) of Berkeley and Technoscan Inc of Salt Lake City with the support of an SBIR contract. The single-hole, 3-D, 2-receiver tool was able to detect resistivity changes that were comparable to those obtained with the ERT method.

An earlier imaging experiment involved the use of a Lawrence Berkeley ground penetrating radar tool (GPR) at the Vadose Zone Observatory. The cross-borehole system was limited by the highly conductive silty soils of the site with observations between holes that were no more than 2-3 meters apart representing the upper limits of separation that could be achieved. The result suggests that no one technique for subsurface imaging is optimal at all contaminated sites of interest.

Implications of the work to date are that the vadose zone may serve as a preferential pathway depending on the chemistry of infiltrating liquids. However, some imbibition inevitably occurs leading to storage of some of the contaminated groundwater in the unsaturated regime. It is this contaminated groundwater that is metered into the saturated zone during an infiltration event. With the aid of ERT serving as our baseline imaging approach, we are learning what kinds of imaging technology are useful for subsurface investigations as well as major drawbacks with other kinds of approaches such as GPR.

With partial support from EMSP, we published a major journal article in Environmental Science \& Technology (ES\&T) on modeling electrical heating in the subsurface. The article was featured on the cover of the November 15, 2000 issue of the journal (Fig. 3). The simulation capability described in the $E S \& T$ article represents one component needed for our future modeling effort to develop a simulator that will allow quantitatively improving subsurface models of infiltration using actual ERT imaging observations.

Finally, in support of DOE educational outreach, our EMSP effort this year included contributions from one master's level intern, David Ralston, from the Defense Nuclear Facilities Safety Board (DNFSB) and a postdoctoral staff member, Brenda Ekwurzel, whose work on our project was credited with helping her to interview successfully for a 
professorship at the University of Arizona. The letter from the DNFSB Chairman, John Conway to Charles Carrigan, acknowledging our project's contributions to Ralston's internship is shown in Figure 4.

\section{Planned Activities}

Future research will continue to include comparisons between the more invasive ERT imaging methods that serve as a baseline and borehole imaging approaches that do not necessarily require drilling new holes at a site. We are seeking to leverage our EMSP program funding in the area of integrating observations into vadose zone models of infiltration and anticipate utilizing observations from the Vadose Zone Observatory to enhance numerical simulations of infiltration at the site.

\section{Information Access}

Carrigan, C.R. and J.J. Nitao, Predictive and diagnostic simulation of in situ electrical heating in contaminated, low permeability soils. Environmental Science \& Technology, 34, 4835-4841, 2000. (Cover article)

Carrigan, C.R., sidebar contributions ( 3 total, p. 943 in particular) to DOE "Vadose Zone, Science \& Technology Solutions",Book published by Battelle Press, 2000.

Carrigan, C.R., Performing vadose zone experiments and interpreting hydrologic observations at Hanford (EMSP 70149). Presented at Advanced Vadose Zone Characterization Workshop, Jan 19-20, 2000, Richland, WA.

Carrigan, C.R., The dynamics of vadose zone transport: A field and modeling study using the Vadose Zone Observatory (70149). Poster (29) presentation for EMSP National Workshop 2000, April 24-28, 2000. Westin Peachtree Plaza, Atlanta, GA.

Carrigan, C.R., Characterization of contaminant transport by gravity, capillarity and barometric pumping in heterogeneous vadose regimes (54950). Poster (30) presentation for EMSP National Workshop 2000, April 24-28, 2000. Westin Peachtree Plaza, Atlanta, GA.

Carrigan, C.R., The LLNL Vadose Zone Observatory: Lessons about contaminant transport and monitoring. Oral presentation for EMSP National Workshop 2000, April 26, 2000. Westin Peachtree Plaza, Atlanta, GA.

Carrigan, C.R., Contaminant migration to the watertable -- A looming societal nightmare. Invited lecture to Center for Subsurface Sensing and Imaging Systems (CenSSIS) Industrial Collaboration Conference, Nov. 13-15, 2000. PowerPoint presentation available at http://www.censsis.neu.edu/mainframe seminar ws01.html 

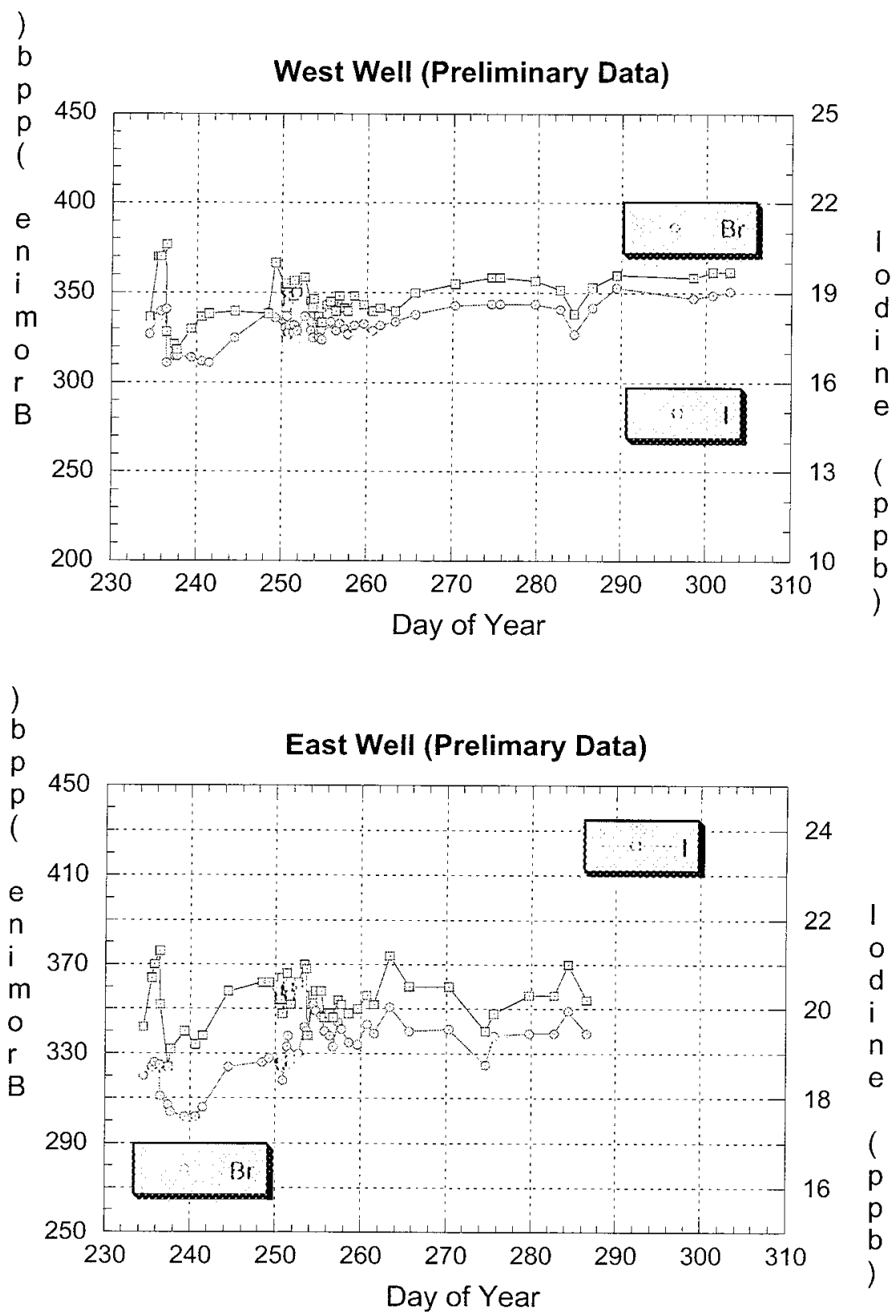

Figure 1 


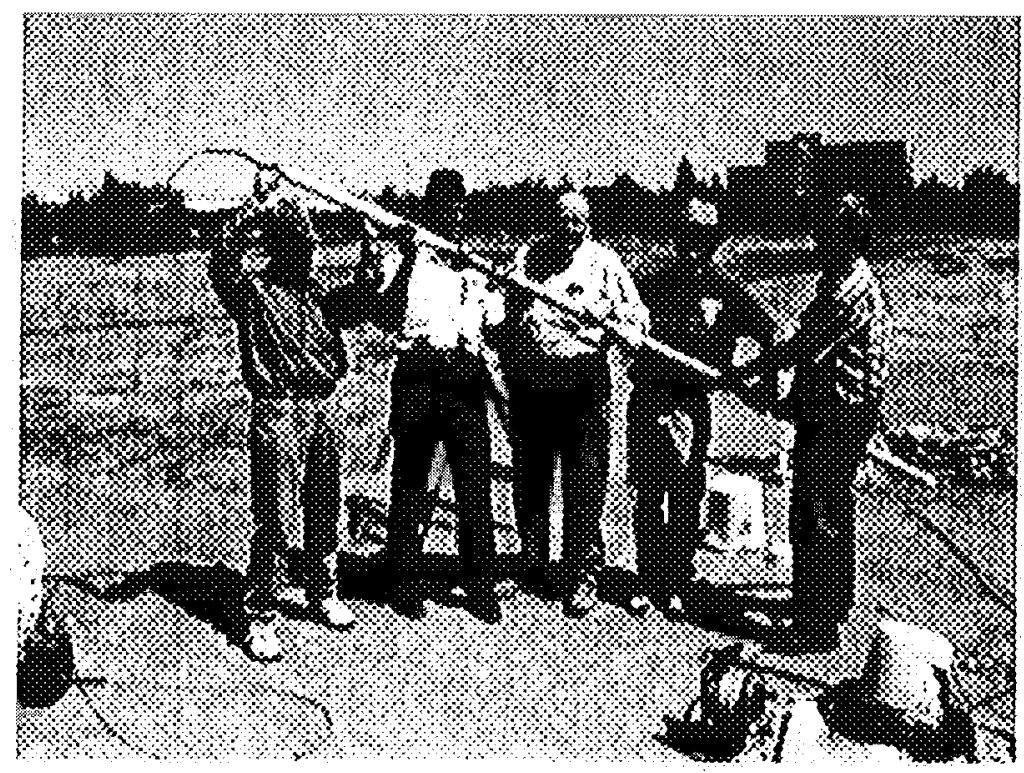

Figure 2

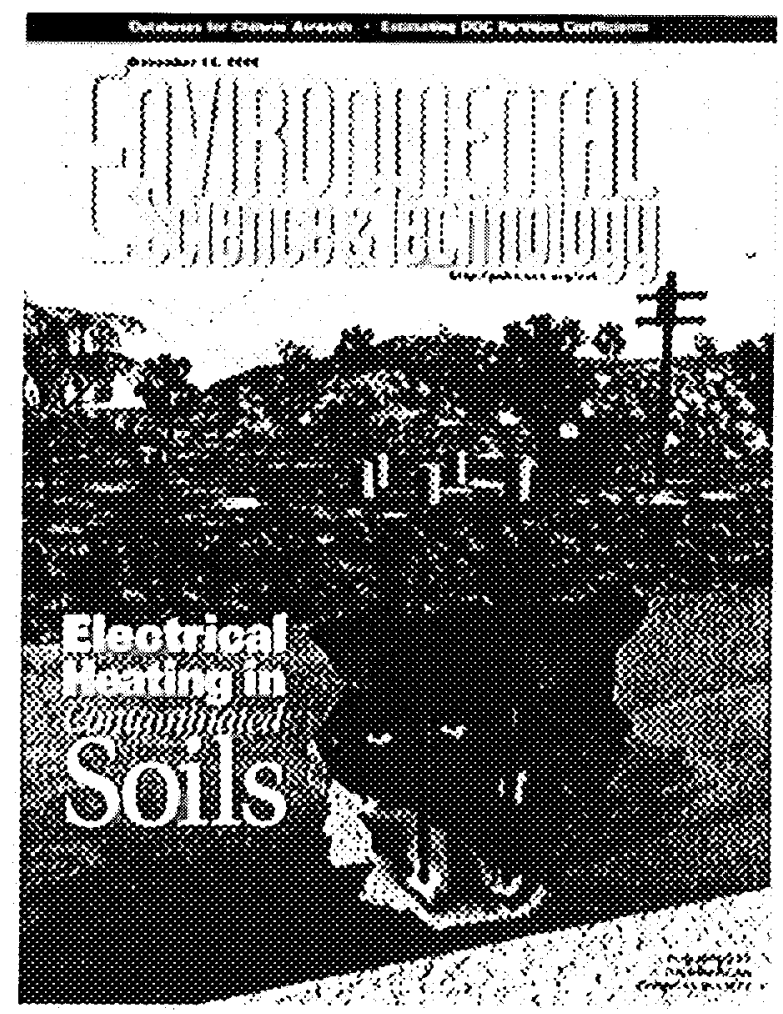

Figure 3 
January 14, 2000

Dr. Charles Carrigan

Geosciences and Environmental Technologies Division

Lawrence Livermore National Laboratory

P.O. Box 808, L-204

Livermore, California 94551

Dear Dr. Carrigan:

The Defense Nuclear Facilities Safety Board (Board) would like to thank you for your efforts in helping to make David Ralston's third-year intern assignment a success. The Board was pleased with the meaningful technical projects you assigned him to work on with the Geosciences and Environmental Technologies Division. The experience he gained with numerical modeling and field testing of flow and transport in the vadose zone will be invaluable in his work for the Board.

Sincerely,

John T. Conway

Chairman

cc: Mr. Michael K. Hooper

Dr. C. Bruce Tarter

Dr. Dennis K. Fisher

Dr. Leland W. Younker

Dr. Kenneth J. Jackson

\section{Figure 4}

